\title{
Agreement Between Waist Hip Ratio and Total Cholesterol to HDL Ratio in the Diagnosis of Raised Total Cholesterol in Post Menopausal Women
}

\section{Muhammad Asif, ${ }^{1}$ Abida Pervaiz, ${ }^{2}$ Wajiha Fatima, ${ }^{3}$ Naseer Umer Bhatti, ${ }^{4}$ Muhammad Iftikhar Yousaf,} Ayesha Mahmood Malik ${ }^{6}$

\begin{abstract}
Objective: To establish the presence of hypercholesterolemia in post-menopausal women by checking an agreement between waist hip ratio (WHR: at a cut off 0.84 ) with total cholesterol to HDL ratio (TC/HDL at a cut off 4).

Methods: This cross-sectional descriptive study was conducted at the department of medicine over a period of 6 months. 225patients fulfilling the inclusion criteria were recruited after explaining the procedure and taking informed consent. $5 \mathrm{ml}$. of an eight hours fasting blood drawn in the serum vial and sent to the laboratory for the analysis of total cholesterol and HDL cholesterol according to the hospital laboratory protocol. Waist and hip measurements taken via a reference point at umbilicus and $5 \mathrm{c} . \mathrm{m}$ below it via a measuring tape.

Results: $112(49.78 \%)$ individuals were from 61-65 years, $69(30.67 \%)$ between $56-60$ and only $44(19.55 \%)$ were between 51-55 years of age. Frequency of agreement between WHR and TC/HDL ratio was calculated which revealed $72.44 \%(\mathrm{n}=163)$ as positive and $27.56 \%(\mathrm{n}=62)$ as negative. Conclusion: It was established that WHR and TC/HDL remains a strong indicator in preventing major cardiovascular events.

Key words: waist hip ratio, total cholesterol to HDL ratio, post-menopausal.
\end{abstract}

\section{Introduction}

$\mathrm{P}$ ost menopause refers to cessation of menstrual flow due to reduced endogenous production of hormones mainly estrogens and progesterone by gonads. These hormones are believed to be protective against atherosclerotic and major cardiac events. Males have relatively more incidence of cardiovascular events in the form of coronary heart disease (CHD) as compared to women due to favorable effects of estrogen on lipids ${ }^{1,2}$ but women with postmenopause have high chances of cardiovascular

\begin{tabular}{|c|c|c|}
\hline 1. & Muhammad Asif & 2. Abida Pervaiz \\
\hline 3. & Wajiha Fatima & Naseer Umer Bhatti \\
\hline $\begin{array}{l}5 . \\
1-3,6\end{array}$ & $\begin{array}{l}\text { Muhammad Iftikhar Yousaf } \\
\text { Medical Unit \#IV, JHL }\end{array}$ & 6. Ayesha Mahmood Malik \\
\hline 4. & Medical Unit 3 Services Hos & tal Lahore \\
\hline
\end{tabular}

Correspondence:

Dr. Abida Pervaiz

Medical Unit IV, Jinnah Hospital, Lahore

abiam22@gmail.com

Submission Date:

1st Revision Date:

Acceptance Date:

26-08-2020

$14-10-2020$

$01-11-2020$ events. ${ }^{3}$ As deficiency of estrogen leads to hypercholesterolemia. One proposed mechanism is changes in the fat cells leading to not only the accumulation of total cholesterol, triglycerides and HDL but changes occurred at the cellular levels as well. Likewise, in premenopausal due to influence of estrogen women fat distribution is more inclined towards the thigh and gluteal region which changes to abdominal type after menopause due to lack of estrogen. ${ }^{4}$ Obesity is an identifiable and curable risk factors for majority of cardiovascular events both fatal and non-fatal. Obesity predisposes one towards metabolic syndrome that includes hyperuricemia, hypertension, impaired glucose tolerance and dyslipidemias. The location of fat deposition is extremely important to establish the relation between disease and obesity. ${ }^{5}$ Various tools available for diagnosing obesity including waist hip ratio, abdominal fat and LDL-c levels. ${ }^{6}$ Serum TC/HDL-C ratio is important in establishing risk of CHD. Ratio of $\geq 4.6$ considered threatening for cardiovascular events so an optimal value of 3.3 is suggested. ${ }^{5}$ Frequency of raised total cholesterol to HDL ratio in postmenopausal women is $30 \%{ }^{8}$. Our study was conducted to screen the post-menopausal 


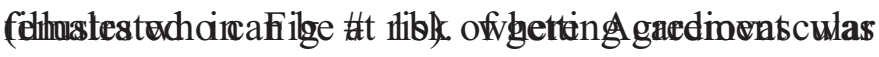

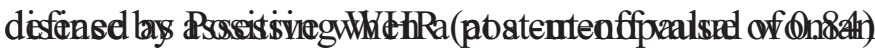
hadīg

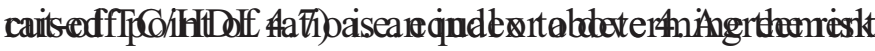

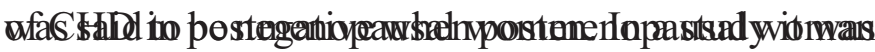

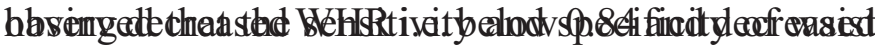

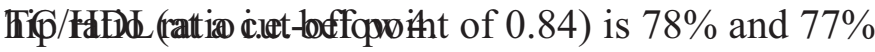

Table 1: Stratification of Agreement as Positive between Whr and Tc/hdl Ratio with Regards to Duration of Disease. $(n=163)$

\begin{tabular}{ccc}
\hline $\begin{array}{c}\text { Duration of disease i.e. post } \\
\text { menopause (in years) }\end{array}$ & $\begin{array}{c}\text { No. of } \\
\text { patients }\end{array}$ & $\begin{array}{c}\text { No. of patients } \\
\text { (\%) }\end{array}$ \\
\hline $\mathbf{1 - 4}$ & 54 & $30(18.40 \%)$ \\
$\mathbf{5 - 8}$ & 78 & $50(30.67 \%)$ \\
$>\mathbf{8}$ & 93 & $83(50.92 \%)$ \\
Total & $\mathbf{2 2 5}$ & $\mathbf{1 6 3}$ \\
\hline
\end{tabular}

Peispanstsicelly in the detection of raised total cholesterol to HDL cholesterol (TC/HDL-C) in postmeno-

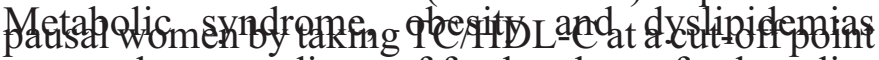

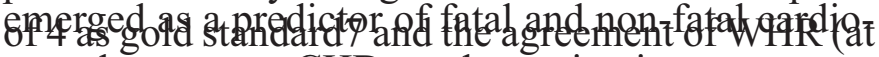

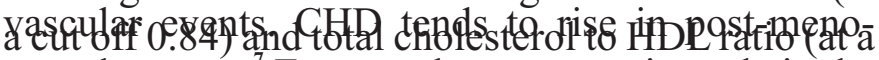
pats $459 \mathrm{~s} \% \%$. Estrogen has a protective role in the prevention of thrombosis with anti-inflammatory

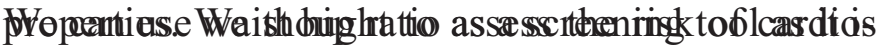

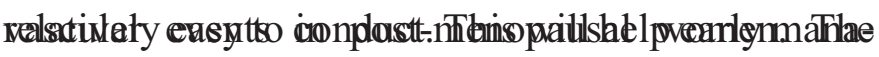

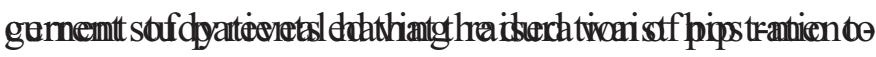

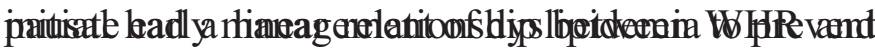
Terdiffly hatint.di6bapatients had a positive agreement between these ratios. The frequency of agreement Betthers $72.44 \%(n=1.63)$ as positive and $27.56 \%(n=62)$ as This descriptive cross-sectional survey was conducnegative our results were consistent.With a study that showed an agreement in $78 \%$ of the patients for Jinnah hospital, Lahore over a period of months via detection of raised total cholesterol to HDL choles a non-probability purposive sampling, after approval trom a focal ethical compostmenopausal 120 nen by trom a ocalthica committe. A total of 251 ndiviguats $95 \%$ confidence levee $190 \%$ margin oferror and dard and the agreement by $W H$ R at a cut off 0.84 ) and taking expected percentage of agreement $1 . e$. $78 \%$, total cholesterol to HDL ratio at a cut off 4 \% b/w waist hip ratio (at a cut off 0.84 ) and total choles-

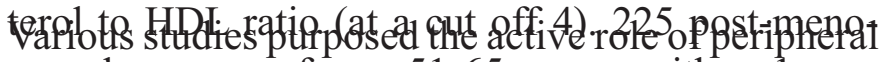

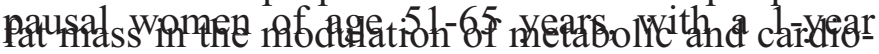

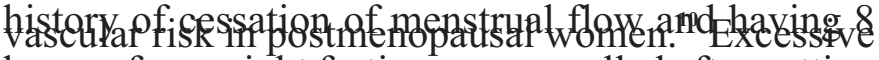

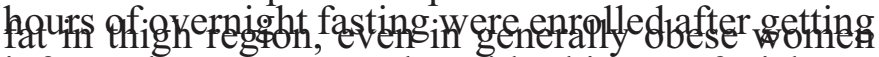
inforrmedessnsentrutemalest,with a bistoryo of Piaketes

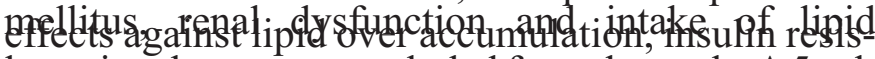

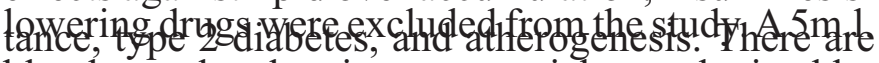

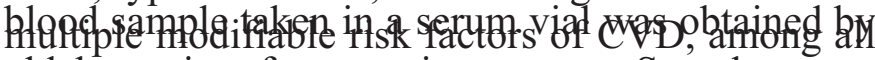
mhlehotiomist after asseptice measure Sambses dxerf

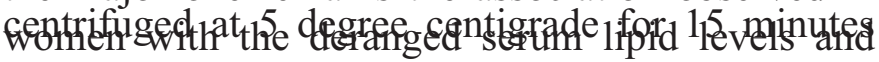

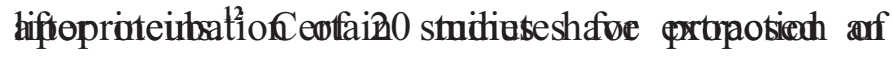

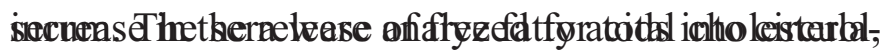

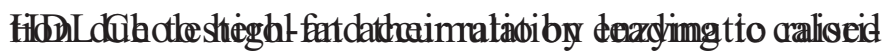

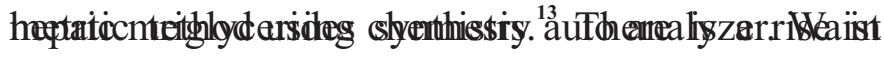

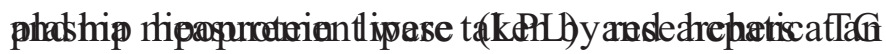

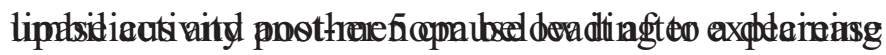

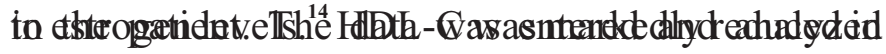

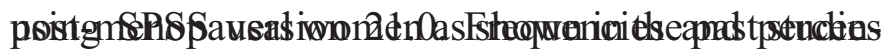

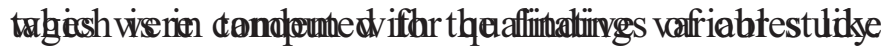

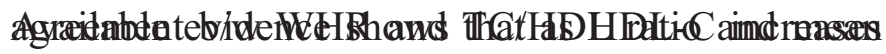
plus0.02\%

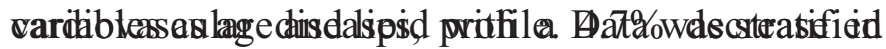

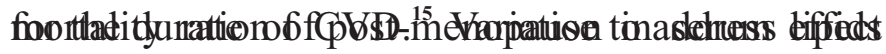

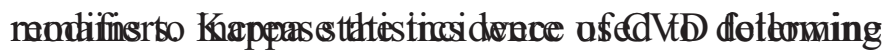
theisoneangttal कfangritiem ent $\mathrm{b} / \mathrm{w}$ WHR (at a cut off 0.84 ) and TC/HDL-C ratio (at a cut off 4 ).

The available data is scanty, while different studies Peccalted that WHR can serve as an easy screening adjunct used in conjunction with other proven mea-

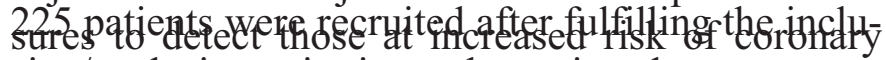

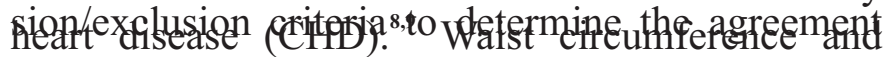

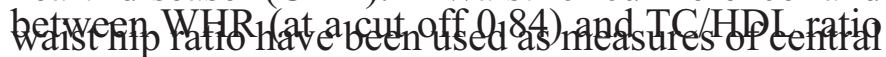

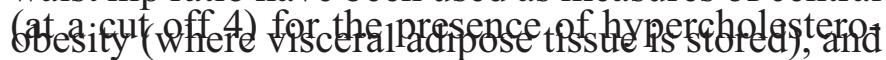

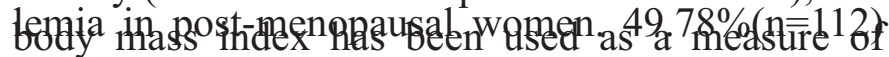
gererabetwest the age group 61-65 years, $30.67 \%$ $(\mathrm{n}=69)$ from $56-60$ years and $19.55 \%(\mathrm{n}=44)$ were

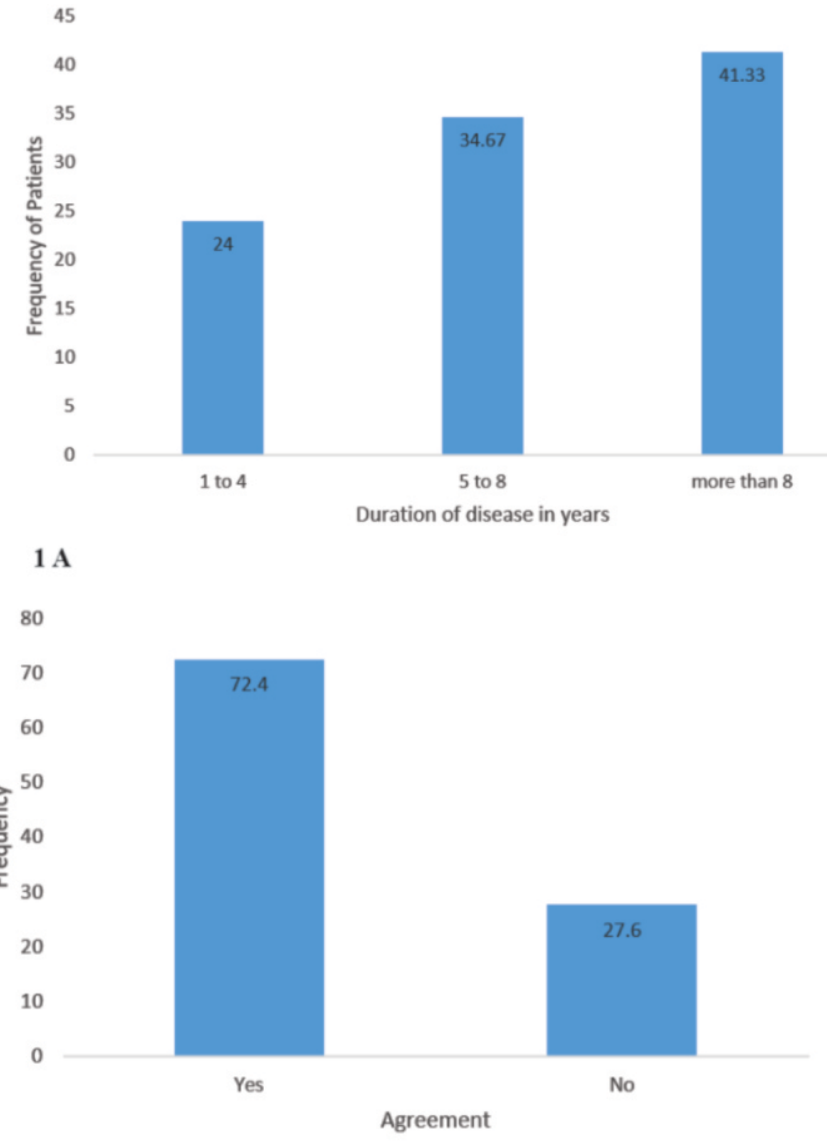

1 B 
(illustrated in Fig \# 1b). where Agreement was defined as Positive when a post-menopausal woman having increased WHR i.e. equal or above 0.84 and raised TC/HDL ratio i.e. equal or above 4. Agreement was said to be negative when postmenopausal woman having decreased WHR i.e. below 0.84 and decreased TC/HDL ratio i.e. below 4.

Table 1: Stratification of Agreement as Positive between Whr and Tc/hdl Ratio with Regards to Duration of Disease. $(n=163)$

\begin{tabular}{ccc}
\hline $\begin{array}{c}\text { Duration of disease i.e. post } \\
\text { menopause (in years) }\end{array}$ & $\begin{array}{c}\text { No. of } \\
\text { patients }\end{array}$ & $\begin{array}{c}\text { No. of patients } \\
(\mathbf{\%})\end{array}$ \\
\hline $\mathbf{1 - 4}$ & 54 & $30(18.40 \%)$ \\
$\mathbf{5 - 8}$ & 78 & $50(30.67 \%)$ \\
$>\mathbf{8}$ & 93 & $83(50.92 \%)$ \\
Total & $\mathbf{2 2 5}$ & $\mathbf{1 6 3}$ \\
\hline
\end{tabular}

\section{Discussion}

Metabolic syndrome, obesity and dyslipidemias emerged as a predictor of fatal and non-fatal cardiovascular events. CHD tends to rise in post-menopausal women. ${ }^{7}$ Estrogen has a protective role in the prevention of thrombosis with anti-inflammatory properties. We thought to assess the risk of cardiovascular events in post-menopausal women. The current study revealed that the duration of post-menopausal had a linear relationship between WHR and TC/HDL ratio. 163 patients had a positive agreement between these ratios. The frequency of agreement between WHR and TC/HDL ratio was calculated in $72.44 \%(n=163)$ as positive and $27.56 \%(n=62)$ as negative. Our results were consistent with a study that showed an agreement in $78 \%$ of the patients for detection of raised total cholesterol to HDL cholesterol (TC/HDL-C) in postmenopausal women by taking TC/HDL-C at a cut-off point of 4 as gold standard and the agreement by WHR(at a cut off 0.84 ) and total cholesterol to HDL ratio (at a cut off 4$){ }^{5}$

Various studies purposed the active role of peripheral fat mass in the modulation of metabolic and cardiovascular risk in postmenopausal women. ${ }^{10}$ Excessive fat in thigh region, even in generally obese women with excessive truncal fat, can provide protective effects against lipid over accumulation, insulin resistance, type 2 diabetes, and atherogenesis. There are multiple modifiable risk factors of CVD, among all the major one remains the association observed in women with the deranged serum lipid levels and lipoproteins. ${ }^{12}$ Certain studies have proposed an increase in the release of free fatty acids into circulation due to high-fat accumulation leading to raised hepatic triglycerides synthesis. ${ }^{13}$ There is a rise in plasma lipoprotein lipase (LPL) and hepatic TG lipase activity post-menopause leading to a decrease in estrogen levels. ${ }^{14}$ HDL-C was markedly reduced in post-menopausal women as shown in the past studies which is in tandem with the findings of our study. Available evidence shows that as HDL-C increases by $0.026 \mathrm{mmol} / \mathrm{ml}$, there is a reduction in risk of cardiovascular diseases, with a $4.7 \%$ decrease in mortality rate of CVD. ${ }^{15}$ Variation in serum lipids remains to increase the incidence of CVD following menopausal transition. ${ }^{13}$

The available data is scanty, while different studies revealed that WHR can serve as an easy screening adjunct used in conjunction with other proven measures to detect those at increased risk of coronary heart disease (CHD). ${ }^{8,9}$ Waist circumference and waist hip ratio have been used as measures of central obesity (where visceral adipose tissue is stored), and body mass index has been used as a measure of general obesity. ${ }^{10}$

There is a need for more trials for determination of agreement between waist ratio (at a cut off 0.84 ) and total cholesterol to HDL ratio (at a cut off 4 ) in the diagnosis of raised total cholesterol in post-menopausal women are required so that we can use waist hip ratio as a screening tool to detect raised total cholesterol to HDL ratio in post-menopausal women. It will help early management of patients to prevent coronary heart disease.

\section{Conclusion}

It is concluded that post-menopausal state might be a predictor of metabolic syndrome leading to cardiovascular events. The early pharmacological intervention can minimize this risk, so we can stratify the population at risk without any identifiable risk factors.

Author's Contributions

MA, WF: Data Collection

AP: Supervision of research work

NUB, MIY: Data Analysis.

AMM: Review of manuscript 


\section{References}

1. Habib SS, Aslam M, Hameed W. Gender differences in lipids and lipoprotein (a) profile in healthy individuals and patients with type 2 diabetes mellitus. Pak J Physiol 2005; 1:1-2.

2. Verit FF, Zeyrek FY, Zebitay AG, Akyol H. Cardiovascular risk may be increased in women with unexplained infertility. ClinExpReprod Med. 2017; 44(1): 28-32. doi:10.5653/cerm.2017.44.1.28

3. Oliveira MA, Fagundes RL, Moreira EA, Trindade EB, Carvalho T. Relation between anthropometric indicators and risk factors for cardiovascular disease. ArquivosBrasileiros de Cardiologia 2010; 94:47885.

4. Habib SS, Aslam M, Hameed W. Gender differences in lipids and lipoprotein (a) profile in healthy individuals and patients with type 2 diabetes mellitus. Pak J Physiol 2005; 1:1-2.

5. Sultan N, Nawaz M, Sultan A, Fayaz A. Waist hip ratio as an index for identifying women with raised TC/HDL ratios. JAMC 2004; 16(1).

6. Kumar A, Sivakanesan RY. Serum lipid profile abnormality in predicting the risk of myocardial infarction in elderly normolipidaemic patients in South Asia: a case-controlled study. The Int J Altern Med 2009; 6:2.

7. Pardhe BD, Ghimire S, Shakya J, et al.: Elevated Cardiovascular Risks among postmenopausal women: A Community Based Case Control Study from Nepal. Biochem Res Int. 2017; 2017:3824903.

8. Vishal R, Randon RV, Mahajan A. Sharma S, Sharma A. Prevalence of cardiovascular risk factors in postmenopausal women: a rural study. J Midlife Health
2010; 1:26-9.

9. Nakagami T, Qiao Q, Carstensen B. Age, body mass index and type 2 diabetes - associations modified by ethnicity. Diabetologia 2003;46: 1063-70.

10. Tankó LB, Bruun JM, Alexandersen P, Bagger YZ, Richelsen B, Christiansen C, Larsen PJ. Novel associations between bioavailable estradiol and adipokines in elderly women with different phenotypes of obesity: implications for atherogenesis. Circulation. 2004;110: 2246-52.

11. Heitmann BL, Frederiksen P, Lissner L. Hip circumference and cardiovascular morbidity and mortality in men and women. Obes Res.2004;12: 482-7.

12. Nwagha UI, Ikekpeazu EJ, Ejezie FE, et al.: Atherogenic index of plasma as useful predictor of cardiovascular risk among postmenopausal women in Enugu, Nigeria. Afr Health Sci. 2010; 10(3): 248-52.

13. Tankó LB, Bagger YZ, Qin G, et al.: Enlarged waist combined with elevated triglycerides is a strong predictor of accelerated atherogenesis and related cardiovascular mortality in postmenopausal women. Circulation. 2005; 111(15): 1883-1890.

14. Wakatsuki A, Okatani Y, Ikenoue N, et al.: Effect of lower dose of oral conjugated equine estrogen on size and oxidative susceptibility of low-density lipoprotein particles in postmenopausal women. Circulation. 2003; 108(7): 808-813.

15. Nwagha UI, Ikekpeazu EJ, Ejezie FE, et al.: Atherogenic index of plasma useful predictor of cardiovascular risk among postmenopausal women in Enugu, Nigeria. Afr Health Sci. 2010; 10(3): 248-52. 